\title{
Inequity in utilization of health care facilities during childbirth: a community-based survey in post-conflict Northern Uganda
}

\author{
David Mukunya ${ }^{1}$ (1) - James K. Tumwine ${ }^{2} \cdot$ Grace Ndeezi $^{2} \cdot$ Josephine Tumuhamye $^{1}$. Justin Bruno Tongun ${ }^{1,3}$. \\ Samuel Kizito ${ }^{4}$ Agnes Napyo ${ }^{5}$. Vincentina Achora ${ }^{6}$. Beatrice Odongkara ${ }^{7}$. Agnes Anna Arach ${ }^{8}$. \\ Victoria Nankabirwa9
}

Received: 20 March 2019 / Accepted: 27 June 2019 / Published online: 10 July 2019

(C) The Author(s) 2019, corrected publication August 2019

\begin{abstract}
Aim To assess inequity in utilization of health care facilities during childbirth and factors associated with home births in Lira district, Northern Uganda.

Subjects and methods In 2016, we surveyed 930 mothers with children under the age of 2 years in Lira district, Northern Uganda. We used multiple correspondence analysis to construct the wealth index in quintiles, based on household assets. The concentration index is the measure of socioeconomic inequality used in this article, which we calculated using the Stata DASP package. We also conducted multivariable logistic regression to assess factors associated with home births.

Results A third of mothers $(n=308)$ gave birth from home [33\%, 95\% confidence interval $(\mathrm{CI})(26 \%-41 \%)$ ]. Giving birth at a health facility was pro-rich with a concentration index of 0.10 [95\% CI (0.05-0.14)]. Upon decomposing the concentration index, the most important determinant of inequity was the mother's residence. Factors associated with home births in multivariable logistic regression included rural residence [adjusted odds ratio (AOR) 3.1, 95\% CI (1.8-5.3)], precipitate labor [AOR 4.18, 95\% CI (2.61-6.71)], and labor starting in the evening or at night. Mothers who had previously given birth from home were more likely to give birth at home again [AOR 40.70, 95\% CI (18.70-88.61)], whereas mothers who had experienced a complication during a previous birth were less likely to give birth at home [AOR $0.45,95 \%$ CI $(0.28-0.95)$ ].
\end{abstract}

David Mukunya

zebdaevid@gmail.com

James K. Tumwine

kabaleimc@gmail.com

Grace Ndeezi

gndeezi@gmail.com

Josephine Tumuhamye

tphynne@gmail.com

Justin Bruno Tongun

tongunmafi@gmail.com

Samuel Kizito

somekizito@yahoo.com

Agnes Napyo

napyoagnes@gmail.com

Vincentina Achora

vincentachora@gmail.com

Beatrice Odongkara

beachristo2003@gmail.com
Agnes Anna Arach

Arachaa2000@gmail.com

Victoria Nankabirwa

nankabirwav@gmail.com

1 Center for International Health, University of Bergen,

Bergen, Norway

2 Department of Pediatrics and Child Health, School of Medicine, College of Health Sciences, Makerere University, Kampala, Uganda

3 Department of Pediatrics, University of Juba, Juba, South Sudan

4 Clinical Epidemiology Unit, School of Medicine, College of Health Sciences, Makerere University, Kampala, Uganda

5 Department of Public Health, Busitema University, Mbale, Uganda

6 Department of Obstetrics and Gynecology, University of Gulu, Gulu, Uganda

7 Department of Pediatrics, University of Gulu, Gulu, Uganda

8 Department of Nursing, Lira University, Lira, Uganda

9 Department of Epidemiology and Biostatistics, School of Public Health, College of Health Sciences, Makerere University, Kampala, Uganda 
Conclusion There was inequity in the utilization of health facilities for childbirth. Programs that promote health facility births should prioritize poorer mothers and those in rural areas.

Keywords Inequity $\cdot$ Home births $\cdot$ Uganda $\cdot$ Post-conflict $\cdot$ Health facility birth $\cdot$ Hospital delivery

\section{Background}

Universal health coverage has been adopted as a composite health output for countries aiming to achieve Goal 3 of the Sustainable Development Agenda, which was adopted by all nations under the United Nations umbrella (United Nations General Assembly 2015). Universal health coverage means that everyone has access to the health care they need without becoming impoverished in the process (World Health Organization 2010). A major step in achieving universal health coverage is ensuring that vital services, such as for maternal health, are free of charge. Uganda has taken this necessary step. Despite services being free of charge, however, the utilization of health facilities for maternal and child health care in Northern Uganda is still low [Uganda Bureau of Statistics (UBOS) and ICF 2017]. As we move towards universal health coverage, contextualized knowledge on the utilization of health services is needed (Onarheim et al. 2015).

Unfair inequalities in the utilization of health care facilities are termed inequities, especially if such inequalities are potentially amendable through feasible and available means (Macinko and Starfield 2002). Inequity in health is one of the biggest challenges hindering the attainment of universal health coverage (World Health Organization 2010). Inequities exist both between and within countries (Onarheim et al. 2015). Inequities in health care utilization usually favor the rich. Contrary to these expectations, persons from the higher wealth quintiles can also be on the disadvantaged side of health distributions. This was illustrated in an equity study from Eastern Uganda which showed that the rich were less likely to practice exclusive breastfeeding compared with the poor (Eide et al. 2016). Equity analysis helps policy makers and implementers to obtain evidence-based data about where to target specific interventions in order to promote equity, and at whom.

Pathways to health inequity are complex, with various proposed schemes involving the examination of diverse aspects such as the living conditions people are subjected to, income distribution in the country, policies and politics within a country, geographic distribution of the population, health financing priorities, social policies, and cultural views (Macinko and Starfield 2002). Three strategies have been proposed to tackle inequity. The first is increasing health services to those in greatest need, the second is reshaping health financing to favor the disadvantaged, while the third is changing economic policies so that the most disadvantaged benefit (Macinko and Starfield 2002).
Lira district is situated in Northern Uganda. The 20 years (1986 to 2006) of conflict between government forces and the Lord's Resistance Army (LRA) insurgency resulted in the destruction of livelihoods and health system infrastructure in the area (Muyinda and Mugisha 2015). After the war, the immediate response was positive, with government and nongovernment organizations (NGOs) coming to the area to support the broken health system. Nonetheless, most of the NGOs have since withdrawn. Currently, Northern Uganda lags behind the rest of the country in human development indices and has poor health outcomes. For example, compared with the national average of $73 \%$, only $66 \%$ of women in the Lango region in Northern Uganda give birth in a health facility (UBOS and ICF 2017).

To design an equitable intervention to promote health facility utilization during childbirth, we aimed to assess inequity in the utilization of health facilities for childbirth and determine factors associated with home births in the Lira district in post-conflict Northern Uganda.

\section{Methods}

\section{Study design and settings}

This cross-sectional study was conducted in the Lira district located in post-conflict Northern Uganda, which is about $300 \mathrm{~km}$ from Kampala, the capital city. The district has 13 sub-counties, 1 municipality, and 751 villages. Lira district is home to about 400,000 people with the majority living in rural areas and practicing subsistence farming. Most people in Lira use the government health system. In the Ugandan health care system, caesarean sections can only be performed at level-four health centers and referral hospitals, but due to lack of resources this is not always possible. Vaginal births are conducted at level-three health centers, level-four health centers, and referral hospitals. Lira district has 31 government health facilities: 1 referral hospital, 3 health centers at level four, 17 health centers at level three, and 10 health centers at level two. This study was conducted in three sub-counties in Lira district: Aromo, Agali, and Lira municipality. These sub-counties were chosen because they had very poor maternal and child health indicators. Data collection was conducted between September and November 2016. 


\section{Study participants}

We recruited mothers with children under the age of 2 years to represent current users of maternal health care services. Women who were visiting the study area temporarily, as well as recent immigrants, were excluded from the study, since they most likely did not represent the average mother in the study area. We also excluded women with mental health disorders because our study instruments were questionnaire based, and such women were not in a position to give us accurate information.

\section{Sample selection and sample size}

We used a two-stage sampling modification of the World Health Organization's Expanded Programme on Immunization (EPI) survey method (Bennett et al. 1991; World Health Organization 2008). Villages in all the selected sub-counties were listed, and we conducted probability proportionate to size sampling. In every village selected, we obtained a sampling frame of all households from the local council chairperson and randomly selected the initial households. After identifying the initial households, we moved from house to house, based on proximity, looking for eligible mothers. This process was continued until the necessary sample size from a village was obtained. In cases where a village failed to raise the required numbers, we moved to the next village. To obtain the minimum sample size, we estimated that $50 \%$ of women gave birth from home, using a design effect of 2 , an alpha (type 1 error) of 5\%, a precision of 5\%, and a nonresponse rate of $15 \%$, and calculated a sample size of 904 women. To enlist an equal number from all 30 villages, we enrolled 31 mothers from each village. This ensured that the sample was self-weighted and that individual weighting would not be needed.

\section{Data collection instruments}

Data were collected during face-to-face interviews, with the help of a mobile phone-based questionnaire technology Open Data Kit (https://opendatakit.org). Fully structured questionnaires contained sections on participant characteristics, previous birth experiences and procedures, care during birth of the last born child, newborn care of the last born child, mother and child morbidity, health-seeking practices, and a household item checklist to assess socioeconomic status. This questionnaire was adapted from one previously used in Eastern Uganda and from Uganda Demographic and Health Survey questionnaires (UBOS and ICF 2018).

\section{Procedure}

Thirty trained research assistants who were knowledgeable about the study area and fluent in the local language, Lango, were trained. Village health team members or other persons as assigned by the local council chairpersons acted as our guides in the community. The guide in each study community introduced the study team and procedure to each visited household. Once an eligible mother was identified, the guide was requested to excuse the team to ensure privacy and confidentiality in subsequent interactions. Written informed consent was then obtained, and then we conducted interviews in a private area at the participants' home. Interviews lasted approximately $1 \mathrm{~h}$. Research assistants also made observations around the household, noting the materials of the floors, roof, and walls and the presence of toilets and running water. If an eligible mother was not found at home, the research assistant returned the next day. If not found on the second day, the relevant mother was replaced in the study sample.

\section{Data analysis}

We used Stata version 14 (http://www.stata.com/stata14/) with survey set command adjusting for the multistage sampling in the analysis. Continuous variables were presented as means and standard deviations. Categorical variables were presented as proportions. Wealth index was calculated using multiple correspondence analysis (Howe et al. 2008) based on: (1) ownership of assets - phone, radio, cupboard, bicycle, motorcycle, house, land; (2) fuel used for cooking; (3) assessment of household dwelling characteristics - material of the floors, roof, walls, and windows, number of rooms, and type of toilet. We used multiple correspondence analysis because it is the most suitable choice to use when calculating wealth indices from categorical indicators (Howe et al. 2008). To measure relative inequality, we used both the concentration curve and the concentration index, which we calculated using the STATA DASP package. We also used this package for all the other equity-related analyses. The concentration index is defined as twice the area between the concentration curve and the diagonal line of equality (Wagstaff et al. 1991). It measures the extent of health or health care utilization that is systematically associated with socioeconomic status, and it is preferred to other measures of inequality because it reflects the experiences of the entire population as well as the socioeconomic dimension in health inequities (Wagstaff et al. 1991). The concentration index is represented by the formula:

$C=\frac{2}{\mu} \operatorname{Cov}(h, r)$ 
where $\mathrm{C}$ is the concentration index, $2 \mathrm{Cov}(\mathrm{h}, \mathrm{r})$ is twice the covariance between the health utilization variable $(h)$ and the fractional rank of the person in the living standard distribution $(\mathrm{r})$, and $\mu$ is the mean of the health care utilization variable (Memirie et al. 2016; O'Donell et al. 2008). A positive concentration index indicates that the health variable is more concentrated among the rich, while a negative concentration index shows that the health variable is more concentrated among the poor (Wagstaff et al. 1991). We further decomposed the concentration index, using the Shapley approach, to measure the contribution of three main determinants of health facility utilization, namely education, residence, and age (van Doorslaer et al. 2004; Wagstaff et al. 2003). This method of decomposition uses a linear regression model (ordinal least squares), which was not the most appropriate since our health variable was a binary outcome. However, due to the complexity and error proneness of non-linear models, other authors report have reported successfully using linear models with a binary variable and state that results from linear and non-linear models are similar (Memirie et al. 2016). An alternative to using linear regression is the generalized linear model, specifying the binomial family, and an identity link (Yiengprugsawan et al. 2010). Using the generalized linear model, we came to exactly the same conclusions as with linear regression. We also utilized the concentration curve to give a graphical representation of the share of home births accounted for by cumulative proportions of individuals ranked from poorest to richest (O'Donell et al. 2008). To measure absolute inequality differences, we used the percentage difference between the highest and lowest wealth quintiles (Barros and Victora 2013). We also used bi- and multivariable logistic regression to determine factors associated with home births among our participants. We constructed two multivariable models. The first model consisted of all mothers, whereas the second model consisted only of mothers who had more than one birth experience.

\section{Ethics}

We obtained ethics approval from the School of Medicine Research and Ethics Committee of Makerere University (SOMREC 2015-121) as well as the Uganda National Council of Science and Technology. Written informed consent was obtained from all individual participants included in the study. In cases where the participant could not write, a thumbprint was obtained. The consent form was translated into the local language, Lango, to ensure that participants understood what they were signing. Data were kept confidential, in password-protected computers, and all other materials were kept under lock and key. Direct identifiers such as names were not used in data analysis and dissemination to ensure confidentiality.

\section{Results}

\section{Participant characteristics}

A total of 930 mother-child pairs were included in the analysis. The response rate was $93 \%$. The majority (> $95 \%$ ) of non-respondents were mothers who were absent from their homestead. The mean (standard deviation, SD) child age was 11.2 (7.7) months. The mean (SD) maternal age was 25.8 (5.9) years. Most mothers and fathers had only primary education. Most of the women $(62 \%, n=$

Table 1 Baseline characteristics of mothers surveyed in Lira district, Northern Uganda

\begin{tabular}{|c|c|}
\hline Variable & $\begin{array}{l}\text { Participants }(n=930) \\
n(\%)\end{array}$ \\
\hline \multicolumn{2}{|l|}{ Place of birth } \\
\hline Government hospital & $260(28.0)$ \\
\hline Government health center & $299(32.2)$ \\
\hline Private health facility & $62(6.7)$ \\
\hline Home & $309(33.2)$ \\
\hline \multicolumn{2}{|l|}{ Mother's age } \\
\hline$\leq 19$ & $157(16.9)$ \\
\hline $20-24^{-}$ & $303(32.6)$ \\
\hline $25-29$ & $218(23.4)$ \\
\hline $30-34$ & $145(15.6)$ \\
\hline$\geq 35$ & $107(11.5)$ \\
\hline \multicolumn{2}{|l|}{ Mother's education } \\
\hline None & $102(11.0)$ \\
\hline Primary & $729(78.4)$ \\
\hline Secondary & $83(08.9)$ \\
\hline Tertiary & $16(01.7)$ \\
\hline \multicolumn{2}{|l|}{ Paternal education } \\
\hline None & $24(02.8)$ \\
\hline Primary & $524(61.4)$ \\
\hline Secondary & $228(26.7)$ \\
\hline Tertiary & $77(09.0)$ \\
\hline \multicolumn{2}{|l|}{ Marital status } \\
\hline Single & $77(08.3)$ \\
\hline Married & $853(91.7)$ \\
\hline \multicolumn{2}{|l|}{ Maternal employment } \\
\hline Yes & $329(38.0)$ \\
\hline No & $537(62.0)$ \\
\hline \multicolumn{2}{|l|}{ Parity } \\
\hline 1 & $227(24.4)$ \\
\hline $2-3$ & $298(32.0)$ \\
\hline$\geq 4$ & $405(43.6)$ \\
\hline \multicolumn{2}{|l|}{ Residence } \\
\hline Rural & $589(63.3)$ \\
\hline Urban & $341(36.7)$ \\
\hline \multicolumn{2}{|c|}{ Baby born at term (37 or more WOA) } \\
\hline No & $49(05.3)$ \\
\hline Yes & $881(94.7)$ \\
\hline \multicolumn{2}{|c|}{ Who decides where mother gives birth } \\
\hline Other & $641(68.9)$ \\
\hline Mother & $289(31.1)$ \\
\hline \multicolumn{2}{|l|}{ Mode of birth } \\
\hline Vaginal & $894(96.1)$ \\
\hline Cesarean & $36(3.9)$ \\
\hline \multicolumn{2}{|l|}{ Duration of labor (hours) } \\
\hline$<3$ & $140(15.1)$ \\
\hline $3-24$ & $718(77.2)$ \\
\hline$>24$ & $72(7.7)$ \\
\hline
\end{tabular}

$n$ : absolute numbers

WOA: weeks of amenorrhea 
Fig. 1 Concentration curve showing distribution of facility births in Lira district, post-conflict Northern Uganda. a Blue line: line of equality; b red curve: concentration curve

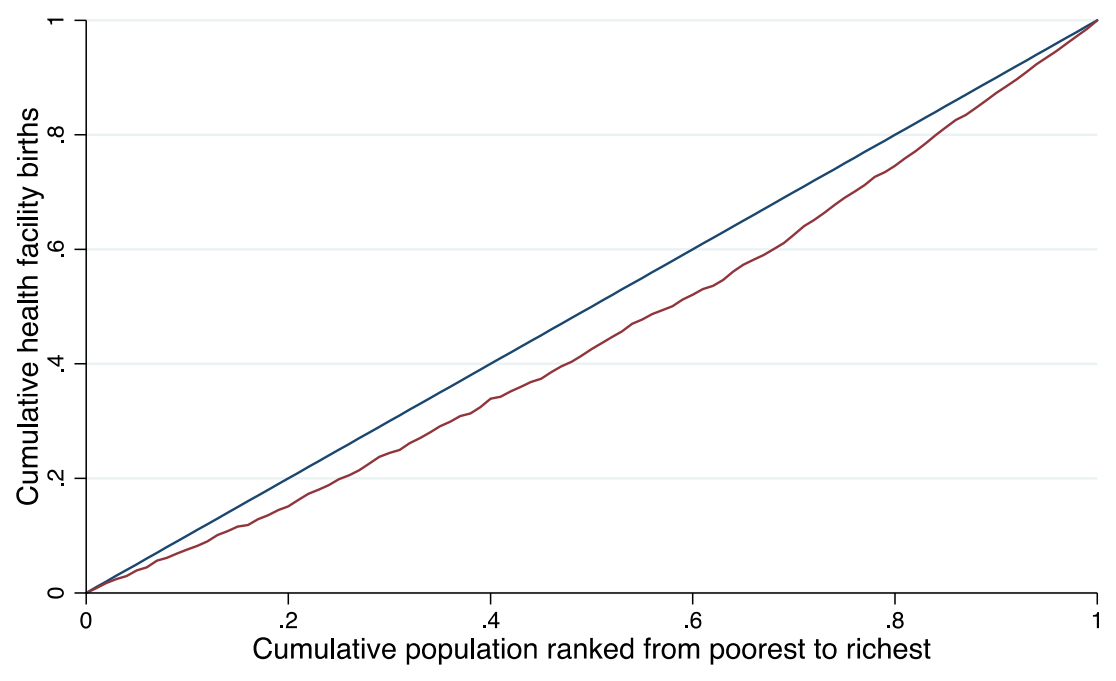

537) were not earning any money, and $44 \%(n=405)$ had so far given birth to four or more children (Table 1).

\section{Bi-variable analysis}

Overall, one third $(n=308)$ of mothers gave birth from home [33\%, 95\% CI (26\%-41\%)].

Of the mothers in the poorest quintile, 54\% gave birth in a health facility, while of those in the richest quintile $87 \%$ gave birth in a health facility, accounting for an absolute difference of 33 percentage points. Giving birth at a health facility was pro-rich (Fig. 1), concentration index $0.10,95 \%$ CI $(0.05-0.14)$. Inequalities in residence, maternal education, and maternal age all favored the rich, but it was mainly residence that was a significant

Table 2 Inequity in utilization of health facilities for childbirth by selected maternal characteristics among mothers in Lira district, Northern Uganda

\begin{tabular}{ll}
\hline Maternal characteristic & Concentration index \\
\hline Mother's age (years) & \\
$\leq 19$ & $0.03(-0.04-0.10)$ \\
$20-24$ & $0.10(0.04-0.16)$ \\
$25-29$ & $0.15(0.09-0.20)$ \\
$30-34$ & $0.10(0.02-0.17)$ \\
$\geq 35$ & $0.15(0.05-0.24)$ \\
Mother's education & \\
None & $0.11(0.01-0.20)$ \\
Primary & $0.08(0.04-0.13)$ \\
Secondary & $0.10(0.02-0.18)$ \\
Tertiary & $0.09(-0.06-0.24)$ \\
Residence & \\
$\quad$ Rural & $0.05(0.001-0.10)$ \\
$\quad$ Urban & $0.04(0.02-0.06)$ \\
$\quad$ Population (total) & $0.10(0.05-0.14)$ \\
\hline
\end{tabular}

determinant of inequity in health facility utilization (Tables 2 and 3). Factors associated with home birth at the bi-variable level included belonging to a lower wealth quintile, having either no or primary education compared with secondary and tertiary, higher parity, rural residence, and precipitate labor and previous home birth, among others (Table 4).

\section{Multivariable analysis}

Factors associated with home births in multivariable logistic regression included: rural residence [AOR 3.1, 95\% CI (1.8-5.3)], mother mainly deciding place of birth [AOR 1.7, 95\% CI (1.2-2.5)], precipitate labor [AOR $4.18,95 \%$ CI (2.6-6.71)], and labor starting in the evening or at night. Wealthier mothers were less likely to give birth at home (Table 4).

The model that only included mothers with more than one birth experience showed similar results to the full model (Table 3). In addition, this model showed that mothers who had previously given birth from home were more likely to give birth at home again [AOR 40.70, 95\% CI (18.70-88.61)], whereas mothers who had ever experienced a delivery complication were less likely to give birth at home [AOR 0.45, 95\% CI (0.28-0.95)] (Table 4).

Table 3 Decomposition of concentration index by selected maternal characteristics in Lira district, Northern Uganda

\begin{tabular}{lll}
\hline Maternal characteristics & Absolute contribution & Relative contribution \\
\hline Constant & 0.00 & 0.00 \\
Residence & 0.09 & 0.28 \\
Maternal education & 0.01 & 0.02 \\
Maternal age & 0.02 & 0.05 \\
Residual & 0.22 & 0.65 \\
Total & 0.33 & 1.00 \\
\hline
\end{tabular}




\section{Discussion}

We found that a third of the mothers gave birth from home, which was much higher than the national average. The estimated national average for non-health facility births in Uganda is one quarter of all births (UBOS and ICF 2017). We also found inequity in the utilization of health facilities, with richer mothers more likely to give birth in a health facility. This is in agreement with the observation that even among poor communities, the richer members often have greater access to health interventions (Barros et al. 2012). Inequity in utilization of health facilities for childbirth has also been observed in Ethiopia where skilled attendance at birth has been associated with higher wealth, education, and urban residence (Bobo et al. 2017; Onarheim et al. 2015). Similar findings have also been found in Bangladesh (Zere et al. 2013), Afghanistan (Akseer et al. 2016), South Africa (Wabiri et al.

Table 4 Factors associated with home delivery at bi- and multivariable analysis among mothers in Lira district, Northern Uganda

\begin{tabular}{|c|c|c|c|c|}
\hline Variable & $\begin{array}{l}\text { Bi-variable } n=930 \\
\text { OR }(95 \% \mathrm{CI})\end{array}$ & $P$ value & $\begin{array}{l}* \text { Multivariable } n=930 \\
\text { AOR }(95 \% \mathrm{CI})\end{array}$ & $\begin{array}{l}* * \text { Multivariable } n=703 \\
\text { AOR }(95 \% \mathrm{CI})\end{array}$ \\
\hline \multicolumn{5}{|l|}{ Mother's age (years) } \\
\hline$\leq 24$ & 1 & & 1 & 1 \\
\hline$\geq 25$ & $1.46(1.15-1.85)$ & 0.003 & $1.26(0.82-1.93)$ & $1.40(0.75-2.64)$ \\
\hline \multicolumn{5}{|l|}{ Mother's education } \\
\hline None & 1 & & 1 & 1 \\
\hline Primary & $0.73(0.47-1.11)$ & 0.138 & $1.10(0.70-1.71)$ & $0.88(0.53-1.46)$ \\
\hline Secondary & $0.37(0.15-0.93)$ & 0.035 & $0.88(0.35-2.24)$ & $1.41(0.50-4.02)$ \\
\hline Tertiary & $0.33(0.10-1.08)$ & 0.066 & $1.23(0.34-4.46)$ & $0.58(0.08-4.31)$ \\
\hline \multicolumn{5}{|l|}{ Father's education } \\
\hline None & 1 & & & \\
\hline Primary & $0.96(0.38-2.42)$ & 0.935 & & \\
\hline Secondary & $0.65(0.26-1.60)$ & 0.336 & - & - \\
\hline Tertiary & $0.58(0.20-1.71)$ & 0.314 & & \\
\hline \multicolumn{5}{|l|}{ Wealth index } \\
\hline 1 (poorest) & 1 & & 1 & 1 \\
\hline 2 & $0.80(0.55-1.18)$ & 0.258 & $0.70(0.46-1.06)$ & $0.71(0.30-1.64)$ \\
\hline 3 & $0.72(0.45-1.15)$ & 0.160 & $0.68(0.40-1.13)$ & $0.60(0.31-1.16)$ \\
\hline 4 & $0.46(0.29-0.72)$ & 0.002 & $0.47(0.31-0.71)$ & $0.46(0.25-0.87)$ \\
\hline 5 (richest) & $0.18(0.11-0.31)$ & $<0.001$ & $0.30(0.17-0.52)$ & $0.28(0.13-0.61)$ \\
\hline \multicolumn{5}{|l|}{ Marital status } \\
\hline Single & 1 & & & \\
\hline Married & $1.18(0.62-2.25)$ & 0.609 & - & - \\
\hline \multicolumn{5}{|l|}{ Parity } \\
\hline 1 & 1 & & 1 & \\
\hline $2-3$ & $1.55(1.08-2.21)$ & 0.019 & $1.32(0.88-2.00)$ & 1 \\
\hline$\geq \quad 4$ & $2.03(1.50-2.74)$ & $<0.001$ & $1.46(0.85-2.51)$ & $0.45(0.28-0.72)$ \\
\hline \multicolumn{5}{|l|}{$\bar{R}$ Residence } \\
\hline Urban & 1 & & 1 & 1 \\
\hline Rural & $4.40(2.59-7.49)$ & $<0.001$ & $3.05(1.77-5.25)$ & $2.86(1.39-5.86)$ \\
\hline \multicolumn{5}{|c|}{ Who decided where mother should give birth? } \\
\hline Mother & $1.75(1.28-2.39)$ & 0.001 & $1.72(1.19-2.48)$ & $2.29(1.48-3.53)$ \\
\hline Other person & 1 & & 1 & 1 \\
\hline \multicolumn{5}{|l|}{ Mother earning money } \\
\hline Yes & $0.87(0.63-1.21)$ & 0.402 & - & - \\
\hline No & 1 & & & \\
\hline \multicolumn{5}{|l|}{ Time labor started } \\
\hline Day (> 6 a.m. to 5 p.m.) & 1 & & 1 & 1 \\
\hline Evening (> 5 p.m. to 10 p.m.) & $1.60(1.15-2.22)$ & 0.006 & $1.79(1.28-2.50)$ & $1.75(1.13-2.72)$ \\
\hline Night (> 10 p.m. to 6 a.m.) & $1.22(0.88-1.70)$ & 0.217 & $1.43(1.00-2.04)$ & $1.57(1.02-2.42)$ \\
\hline \multicolumn{5}{|c|}{ Precipitate labor (duration of labor $<3 \mathrm{~h}$ ) } \\
\hline Yes & $3.53(2.52-4.95)$ & $<0.001$ & $4.18(2.61-6.71)$ & $4.43(2.61-7.52)$ \\
\hline No & 1 & & 1 & 1 \\
\hline \multicolumn{5}{|l|}{ Previous home birth $(n=703)^{\wedge}$} \\
\hline Yes & $29.8(15.6-57.1)$ & $<0.001$ & - & $40.70(18.70-88.61)$ \\
\hline No & 1 & & & 1 \\
\hline \multicolumn{5}{|c|}{ Complications during previous birth $(n=703)^{\wedge}$} \\
\hline Yes & $0.51(0.28-0.93)$ & 0.030 & - & $0.45(0.22-0.95)$ \\
\hline No & 1 & & & 1 \\
\hline
\end{tabular}

*Multivariable model including all mothers

**Multivariable model including only mothers who had more than one childbirth experience

${ }^{\wedge}$ Only asked of mothers with more than one birth experience

$n$ : absolute numbers

OR: odds ratio

AOR: adjusted odds ratio 
2016), and the sub-Saharan African nations of Kenya, Tanzania, and Zambia (Ng'anjo Phiri et al. 2014). Inequities make the achievement of maternal health targets, and consequently universal health coverage, more difficult (Onarheim et al. 2015).

In this study, a variety of reasons could explain the observed inequity in utilization of health facilities. Financial barriers faced by poorer women could be one of the causes of the inequalities when using health facilities for childbirth (Barros et al. 2012). In countries such as Uganda, which have no direct out-of-pocket expenses for accessing maternity services, poorer women still usually face challenges meeting the indirect costs associated with birth. These include transport to the health facility, buying the necessary baby clothing, and 'appreciating' health workers (Treacy et al. 2018). Another potential explanation could be negative cultural perceptions regarding modern medicine (Barros et al. 2012), which are often more common among poorer members in the community.

However, mothers who do not utilize health facilities are more likely to develop complications during birth, which could in turn aggravate poverty (Wagstaff 2002). Upon decomposing the concentration index across three major determinants of health facility utilization during birth, only residence was a significant contributor to the total inequity. Maternal education and age contributed very little to the total concentration index. The residual contribution was $65 \%$, which prompted us to conduct multivariable analysis to determine other factors associated with home births.

Mothers who had previously ever given birth from home were 40 times more likely to give birth from home again. Similar findings have been observed in Ethiopia (Wako and Kassa 2017). Mothers who have ever given birth from home before may lack the motivation to go to health facilities in situations where they have low trust in the services provided and when assess to the health facility is difficult. Mothers experiencing evening/nighttime onset of labor or precipitate labor were more likely to give birth at home. These findings suggest that access to health facilities may be a major problem, especially in the rural areas where poor transport infrastructure discourages mothers from seeking health care in the night. Mothers in rural areas were twice as likely to give birth from home compared with mothers in urban areas. Rural areas tend to have fewer health facilities and health care workers than urban areas. In addition, infrastructure is often poor in rural areas (Treacy et al. 2018; Wilunda et al. 2014). Roads leading to health facilities are often only made of gravel, poorly lit, and non-functional in the rainy season (Treacy et al. 2018). This discourages women from seeking health care, especially if labor starts in the night. These findings have also been observed in other low-income countries such as Sierra Leone (Treacy et al. 2018).

Mothers who bore the main responsibility for deciding the place of birth were twice as likely to give birth from home compared with mothers who had another person (usually the husband) making the decision. This is in contrast to what we expected to see. We had heard anecdotal reports from our study sites that mothers were pressured to give birth from home by their mothers-in-law. This finding suggests that significant others are very important in ensuring that mothers give birth from health facilities and should be included in programs that promote health facility birth. A study conducted in Northern Uganda identified husband support as a major determinant to skilled birth attendance during labor (Anastasi et al. 2015).

One limitation to this study was the use of an asset-based index for determining socioeconomic status. Asset-based indexes may vary depending on choice of asset and from rural to urban areas (Houweling et al. 2003). However, asset-based indexes have also shown robustness and high correlation with more complex monetary measures (Morris et al. 2000). Another potential drawback was recall limitation since respondents were asked to recollect events, which could have been as far back as 2 years, and may have led to nondifferential misclassification. We did not collect data on distance from homes to the health facility, penetration (availability of health facilities in our study areas), or antenatal attendance and therefore cannot comment on these aspects, which have been shown to be significant factors in health facility utilization in other areas (Goldenberg and McClure 2012). This limits our interpretation of the potential source of the inequities observed. All participants in our study had given birth and therefore required the service, and hence this study was automatically standardized for need.

\section{Conclusion}

There was inequity in the utilization of health facilities since poorer mothers were less likely to use health facilities for childbirth. Programs promoting health facility births in similar settings should prioritize poorer communities. This research also calls for multi-sector approaches involving poverty eradication and girl child education when addressing issues such as health facility births.

Acknowledgements We thank Prof. Ole Frithjof Norheim and Dr. Nathan Nshakira for reading through the first draft of the manuscript.

We also acknowledge Prof. Peter Waiswa and the Iganga-Mayuge Demographic and Health Surveillance Site for providing validated study tools, which we borrowed when designing our study. We especially acknowledge the District Health Office of Lira and the various district, sub-county, parish, and village leaders for their assistance in this study. We appreciate the cooperation of the participants and research assistants in our study.

Author contributions DM, JKT, GN, and VN conceived, designed, and supervised the study, analyzed the data, and wrote the first draft of the manuscript.

IO, JT, JBT, AN, VA, BO, and AAA were instrumental in the design and supervision of the study and drafting of the manuscript.

SK contributed to the analysis of the data and critical revision of the manuscript.

All authors read and approved the final version to be published. 
Funding Funding for this research was provided by the Survival Pluss Project (UGA-13-0030), which is financed under the Norwegian Program for Capacity Development in Higher Education and Research for Development (NORHED) by the Norwegian Agency for Development Cooperation (NORAD).

Data availability Data generated and analyzed during this study are available on request from the Principal Investigator of the Survival Pluss study.

\section{Compliance with ethical standards}

Competing interests The authors declare that they have no conflict of interest.

\section{Consent for publication Not applicable.}

\section{Abbreviations CI, Confidence interval}

Open Access This article is distributed under the terms of the Creative Commons Attribution 4.0 International License (http:// creativecommons.org/licenses/by/4.0/), which permits unrestricted use, distribution, and reproduction in any medium, provided you give appropriate credit to the original author(s) and the source, provide a link to the Creative Commons license, and indicate if changes were made.

\section{References}

Akseer N, Bhatti Z, Rizvi A, Salehi AS, Mashal T, Bhutta ZA (2016) Coverage and inequalities in maternal and child health interventions in Afghanistan. BMC Public Health 16(Suppl 2):797. https://doi. org/10.1186/s12889-016-3406-1

Anastasi E et al (2015) Losing women along the path to safe motherhood: why is there such a gap between women's use of antenatal care and skilled birth attendance? A mixed methods study in northern Uganda. BMC Pregnancy and Childbirth 15:287. https://doi.org/ 10.1186/s12884-015-0695-9

Barros AJ et al (2012) Equity in maternal, newborn, and child health interventions in Countdown to 2015: a retrospective review of survey data from 54 countries. Lancet (London, England) 379:12251233. https://doi.org/10.1016/s0140-6736(12)60113-5

Barros AJ, Victora CG (2013) Measuring coverage in MNCH: determining and interpreting inequalities in coverage of maternal, newborn, and child health interventions. PLoS Med 10:e1001390. https://doi. org/10.1371/journal.pmed.1001390

Bennett S, Woods T, Liyanage W, Smith D (1991) A simplified general method for cluster-sample surveys of health in developing countries. World Health Stat Q 44:98-106

Bobo FT, Yesuf EA, Woldie M (2017) Inequities in utilization of reproductive and maternal health services in Ethiopia. Int J Equity Health 16:105. https://doi.org/10.1186/s12939-017-0602-2

Eide KT, Fadnes LT, Engebretsen IM, Onarheim KH, Wamani H, Tumwine JK, Norheim OF (2016) Impact of a peer-counseling intervention on breastfeeding practices in different socioeconomic strata: results from the equity analysis of the PROMISE-EBF trial in Uganda. Glob Health Action 9:30578. https://doi.org/10.3402/ gha.v9.30578

Goldenberg RL, McClure EM (2012) Disparities in interventions for child and maternal mortality. Lancet (London, England) 379: 1178-1180. https://doi.org/10.1016/s0140-6736(12)60474-7

Houweling TA, Kunst AE, Mackenbach JP (2003) Measuring health inequality among children in developing countries: does the choice of the indicator of economic status matter? Int J Equity Health 2:8. https://doi.org/10.1186/1475-9276-2-8

Howe LD, Hargreaves JR, Huttly SR (2008) Issues in the construction of wealth indices for the measurement of socio-economic position in low-income countries. Emerging Themes in Epidemiology 5:3. https://doi.org/10.1186/1742-7622-5-3

Macinko JA, Starfield B (2002) Annotated Bibliography on Equity in Health, 1980-2001. Int J Equity Health 1, 1

Memirie ST, Verguet S, Norheim OF, Levin C, Johansson KA (2016) Inequalities in utilization of maternal and child health services in Ethiopia: the role of primary health care. BMC Health Serv Res 16:51. https://doi.org/10.1186/s12913-016-1296-7

Morris SS, Carletto C, Hoddinott J, Christiaensen LJ (2000) Validity of rapid estimates of household wealth and income for health surveys in rural Africa. J Epidemiol Community Health 54:381-387

Muyinda H, Mugisha J (2015) Stock-outs, uncertainty and improvisation in access to healthcare in war-torn Northern Uganda. Social Science \& Medicine (1982) 146:316-323. https://doi.org/10.1016/j. socscimed.2015.10.022

Ng'anjo Phiri S et al (2014) Factors associated with health facility childbirth in districts of Kenya, Tanzania and Zambia: a population based survey. BMC Pregnancy and Childbirth 14:219. https://doi.org/10. 1186/1471-2393-14-219

O'Donell O, van Doorslaer E, Wagstaff A, Lindelow M (2008) Analyzing Health Equity Using Household Survey Data: A Guide to Techniques and Their Implementation. The World Bank, Washington, DC

Onarheim KH, Taddesse M, Norheim OF, Abdullah M, Miljeteig I (2015) Towards universal health coverage for reproductive health services in Ethiopia: two policy recommendations. Int J Equity Health 14:86. https://doi.org/10.1186/s12939-015-0218-3

Treacy L, Bolkan HA, Sagbakken M (2018) Distance, accessibility and costs. Decision-making during childbirth in rural Sierra Leone: A qualitative study. PLoS One 13:e0188280. https://doi.org/10.1371/ journal.pone. 0188280

Uganda Bureau of Statistics (UBOS) and ICF (2017) Uganda Demographic and Health Survey 2016: Key Indicators Report. UBOS, and Rockville, Maryland, USA : UBOS and ICF, Kampala, Uganda

Uganda Bureau of Statistics (UBOS) and ICF (2018) Uganda Demographic and Health Survey 2016. UBOS and ICF, Kampala, Uganda and Rockville, Maryland, USA

United Nations General Assembly (2015) Transforming our world: the 2030 Agenda for Sustainable Development. http://www.un.org/ga/ search/view_doc.asp?symbol=A/RES/70/1\&Lang=E. Accessed April $14201 \overline{7}$

van Doorslaer E, Koolman X, Jones AM (2004) Explaining incomerelated inequalities in doctor utilisation in Europe. Health Econ 13: 629-647. https://doi.org/10.1002/hec.919

Wabiri N, Chersich M, Shisana O, Blaauw D, Rees H, Dwane N (2016) Growing inequities in maternal health in South Africa: a comparison of serial national household surveys. BMC Pregnancy and Childbirth 16:256. https://doi.org/10.1186/s12884-016-1048-z

Wagstaff A (2002) Poverty and health sector inequalities. Bull World Health Organ 80:97-105 
Wagstaff A, Paci P, van Doorslaer E (1991) On the measurement of inequalities in health. Social Science \& Medicine (1982) 33:545557

Wagstaff A, van Doorslaer E, Watanabe N (2003) On decomposing the causes of health sector inequalities with an application to malnutrition inequalities in Vietnam. J Econ 112:207-223

Wako WG, Kassa DH (2017) Institutional delivery service utilization and associated factors among women of reproductive age in the mobile pastoral community of the Liban District in Guji Zone, Oromia, Southern Ethiopia: a cross sectional study. BMC Pregnancy and Childbirth 17:144. https://doi.org/10.1186/s12884-017-1325-5

Wilunda $\mathrm{C}$ et al (2014) A qualitative study on barriers to utilisation of institutional delivery services in Moroto and Napak districts, Uganda: implications for programming. BMC Pregnancy and Childbirth 14:259. https://doi.org/10.1186/1471-2393-14-259

World Health Organization (2008) Training for mid-level managers: The EPI coverage survey. WHO Expanded Programe on Immunization, Geneva
World Health Organization (2010) The World Health Report 2010: Health systems financing: the path to universal coverage. World Health Organization, Geneva

Yiengprugsawan V, Lim LL, Carmichael GA, Dear KB, Sleigh AC (2010) Decomposing socioeconomic inequality for binary health outcomes: an improved estimation that does not vary by choice of reference group. BMC Research Notes 3:57. https://doi.org/10. 1186/1756-0500-3-57

Zere E, Suehiro Y, Arifeen A, Moonesinghe L, Chanda SK, Kirigia JM (2013) Equity in reproductive and maternal health services in Bangladesh. Int J Equity Health 12:90. https://doi.org/10.1186/ 1475-9276-12-90

Publisher's note Springer Nature remains neutral with regard to jurisdictional claims in published maps and institutional affiliations. 